\title{
ANÁLISIS DE LA ADSCRIPCIÓN A VALORES
}

\author{
RAFAEL GOBERNADO ARRIBAS \\ Universidad de Málaga
}

PALABRAS CLAVE ADICIONALES

Valores, Cultura, Cultura arbitraria.

\author{
ADDITIONAL KEYWORDS \\ Values, Culture, Arbitrary Culture.
}

\begin{abstract}
RESUMEN. Se desarrolla en este trabajo un esquema teórico que sirve para explicar la adscripción a valores. Ese esquema es generalizable a los demás componentes de la cultura, no sólo a los valores. La adscripción a valores puede explicarse por la biología, la personalidad, la sociedad y la cultura. En la cultura a su vez se encuentran tres elementos ligados también a la citada adscripción: los conocimientos, la cultura arbitraria y la coherencia cultural. El factor que explica con más éxito la adscripción a valores es la cultura arbitraria.
\end{abstract}

SUMMARY. We develop in this paper a theoretical outline which is useful to explain the assignment to values. This assignment may be applied not only to values, but also to the other constituents of culture. Biology, personality, society and culture can explain the assignment to values. In turn, we can also find in culture three elements also related to the above mentioned assignments: knowledge, arbitrary culture and cultural coherence (consistency). Arbitrary culture is the element which provides the best explanation to the assignment of values.

En las páginas que siguen se desarrolla un esquema teórico que sirve para explicar la adscripción a valores de los miembros de una sociedad. La adscripción a valores, en su versión más operativa, puede definirse así: la elección por parte del entrevistado de una respuesta u otra en una pregunta sobre valores. En la medida que los valores constituyen el principal elemento cultural (el más abstracto), el esquema teórico que se propone aquí nace con vocación de generalizarse al resto de los elementos culturales. Se entiende por elemento cultural cualquier aspecto ideacional del comportamiento humano.

E-mail: gobernado@uma.es

Revista Internacional de Sociología (RIS)

Tercera Época, $n^{\circ}$ 33, Septiembre-Diciembre, 2002, pp. 47-66. 
En los estudios sobre valores realizados hasta la fecha no se ha conseguido llegar a una explicación convincente. Los autores se suelen centrar sobre todo en la descripción de su distribución entre la población y en general no tratan el tema de las causas de la adscripción de manera profunda (a título de ejemplo, véanse la mayor parte de los trabajos publicados en: Díez Nicolás y Inglehart, 1994; y en Rokeach, 1979). Aun así, estos trabajos no suelen limitarse a la simple descripción, sino que tratan de ir más allá de dos formas diferentes. Por un lado, se utilizan las variables propias de la estructura social como variables independientes, explicativas, de los valores adoptados, aunque con poco éxito (véase, por ejemplo, Andrés Orizo, 1994, 1996). La proporción de la varianza de los valores explicada por la estructura social es escasa (Kerhofs, 1994: 47).

Por otro lado, aunque sin una separación clara con los anteriores trabajos, se produce una serie de estudios, al igual que antes también descriptivos, que interpretan los valores dentro del propio sistema de valores, es decir sin especial referencia a la estructura social. En este caso no existe verdaderamente intento de explicación de la adscripción a valores. El análisis en este caso se reduce a organizar las respuestas en categorías más abstractas, ya sea en dimensiones valorativas, factores morales o cualquier otro indicador de coherencia interna del citado sistema. Pertenecen a este tipo los trabajos más recientes sobre valores. La idea común a todos ellos es que "de una pregunta concreta no puede extraerse un valor", sino que detrás de un conjunto de ellas se esconden los valores subyacentes (Del Pino y Bericat, 1998: 2-3). Es decir, hay que buscar las estructuras latentes que son más estables y coherentes que las simples respuestas (Torcal Loriente, 1992; Inglehart, Ros y Schwartz, 1995; Inglehart, 1994). En este caso, las dimensiones valorativas, los factores morales o las estructuras latentes, suelen utilizarse, al contrario que antes, como variables explicativas de procesos como la modernización, el desarrollo, etc.

Entrecruzándose con la clasificación anterior, los trabajos sobre valores también se diferencian según el interés que pongan en el sentido que los actores dan a su propia acción. Es decir, según cuenten o no con la opinión de los actores (entrevistados) a la hora de valorar. Aquellos autores que parten de la existencia de estructuras latentes o similares, prescinden del sentido subjetivo de la acción. $\mathrm{El}$ actor valora, pero no lo sabe. En el caso contrario, el valor es reconocido por el actor y es éste el que da sentido al mismo. A este último tipo pertenecen, por ejemplo, los estudios basados en la escala de Rokeach (1979), por simple coherencia metodológica, y, en general, la mayor parte de los estudios de la primera categoría de la clasificación anterior. De cualquier forma, en este aspecto, las posiciones intermedias son más abundantes que las puras. Así, se suele hablar de valores explícitos e implicitos, según se tome conciencia de ellos o no (Williams, 1979: 16); o incluso de mayor grado de complejidad en el grado de consciencia, como es el caso del citado Inglehart (1991) que distingue entre plena consciencia, movilización cognitiva o nivel intermedio, por un lado, y estructura latente de valores o nivel profundo de falta de consciencia por parte del actor, por otro. 
Ahora bien, según nuestro criterio, ni la estructura social ni la coherencia interna del sistema de valores pueden explicar suficientemente la variabilidad de las respuestas a las preguntas sobre valores. En segundo lugar, la consciencia o falta de la misma por parte del actor no es tan importante en el análisis de los valores como la presencia en los mismos de una mayor o menor racionalidad. En los valores hay elementos cognitivos y afectivos; racionalidad e irracionalidad; incorporan a la vez conocimientos y creencias (Williams, 1979: 16). En tercer lugar, aunque los valores no gozan de una realidad objetivada, son sin embargo fácilmente observables, ya que los valores son claramente explícitos (Williams, 1979: 17).

\section{EL MODELO TEÓRICO}

La explicación de la adscripción a valores, es decir, a la respuesta dada a cualquier pregunta sobre valores, ha de buscarse en tres ámbitos tradicionales del análisis sociológico: el social, el cultural y el de la personalidad'. Se trata, por supuesto, de ámbitos analíticos, más propios de la mente del investigador que de la realidad. Como es de esperar, la mayor parte de la explicación a la adscripción a valores habrá que buscarla en el ámbito cultural. A su vez, estos ámbitos mantienen entre sí tanto relaciones causales unidireccionales, como relaciones recíprocas y relaciones independientes; $y$ todo ello ha de enmarcarse en las coordenadas tiempo y espacio correspondientes.

\section{EI ámbito social}

El ámbito social influye en la elección de los valores, aunque en una proporción muy limitada, como se dijo arriba. Dos han sido los mecanismos o nexos causales que, según la tradición sociológica, ligan el ámbito social de análisis con la adscripción a valores y, en general, con los comportamientos más próximos a lo cultural: primero, el interés propio de cada actor; segundo, el interés de unos pocos por dominar a la mayoría.

El enfoque teórico denominado individualismo metodológico (Boudon, 1979 y 1981) es, sin lugar a dudas, el que mejor da cuenta de la relación entre el ámbito social y el cultural. De acuerdo con tal enfoque, los valores responden a intereses de los actores. Así puede explicarse el hecho de que los más favorecidos por la fortuna prefieran adscribirse a una sociedad de libre mercado, mientras que

\footnotetext{
${ }^{1}$ Algo parecido propone Williams (1977), salvo que este autor habla de cuatro tipos de valores: los que se dan en el ámbito biológico (p.ej. la supervivencia), en el de la personalidad, en el social y en el cultural. Nosotros pensamos que este criterio de clasificación de los valores no es útil y que cada valor se explica a la vez desde todos esos ámbitos.
} 
R I S

los menos favorecidos prefieran una sociedad de economía planificada. Ha de existir una relación lógica, racional, que explique, por ejemplo, por qué las amas de casa prefieren, en general, la igualdad de salarios, mientras que las mujeres que trabajan en actividades no manuales prefieren, por el contrario, que haya incentivos salariales y por lo tanto desigualdad salarial. La noción de valor en tanto que "interés" (Perry, 1954) prevalece en este tipo de análisis. El análisis de la relación entre la posición social y la respuesta exige, por lo tanto, tener en cuenta el sentido que para el actor tiene su comportamiento.

Esta forma de entender los valores ayuda a explicar, de paso, el cambio de valores en una población atendiendo al cambio de composición de la estructura social. Si la proporción de beneficiados por la fortuna aumenta, disminuirá la proporción de población que defienda una economía planificada. $\mathrm{O}$, también, el hecho de que cada vez haya más mujeres trabajando en actividades no mamuales, $y$ que disminuya la proporción de amas de casa, influirá a su vez en las preferencias señaladas de la población total. Así, no se trata tanto de un cambio de valores como de un cambio de estructura social. Tengamos en cuenta, sin embargo, que el proceso de sustitución suele realizarse generacionalmente, por lo que el cambio en la adscripción también será de tipo generacional. En otras palabras, en este caso, el análisis de cohortes parece ser más eficaz que el del ciclo vital.

Existe otra opción explicativa de la relación entre el nivel social y el nivel cultural, que se basa en la idea de dominación. Este modelo difiere por completo del anterior, ya que el mantenimiento de la dominación se explica al margen de la voluntad de los actores. De acuerdo con esta teoría de la dominación, una minoría impone una forma de pensar dominante al resto de la población. La escuela de Francfort, apoyada en algunos párrafos de la obra de Marx, es un claro representante de esta tendencia, en particular Horkheimer y Adorno (1971) y Marcuse (1968), así como algunos autores franceses, tales como Baudrillard (1974), Bourdieu y Passeron (1981). El nivel social se estructura en este caso en dos categorías: élite y masa. La cultura imperante en una sociedad así considerada es aquélla que permite reproducir la situación de élite y masa, de generación en generación, sin que los actores lleguen a tener conciencia de ello.

A los autores citados de la escuela de Francfort (Adorno, Horkheimer y Marcuse) les falta clarificar el nexo causal que conduce necesariamente a la dominación por parte de la élite sobre el resto de la sociedad. Este no es el caso de Bourdieu y Passeron, los cuales proponen como mecanismo coordinador de la reproducción al capital cultural, heredado mediante el proceso de socialización propio de la clase acomodada. Este capital cultural opera como un descodificador del mensaje educativo, mensaje que es transmitido a todos por igual en la escuela. Sólo aquellos muchachos que lleven incorporado tal descodificador se enterarán del mensaje escolar y aprovecharán la estancia en las aulas. A su vez, los que tengan éxito en la educación terminarán por ocupar los puestos de élite. En contra del modelo de Bourdieu y Passeron sólo se encuentra la empecinada 
y compleja realidad social, cuyos datos no se corresponden a las previsiones de los autores.

Las críticas al modelo de dominación han sido importantes (véase como resumen, Featherstone, 1992: 271): es exageradamente elitista; es engañosamente individualista, ya que condena a las clases populares a la manipulación; utiliza una distinción marxista falaz, la que se hace entre necesidades verdaderas y necesidades falsas; se olvida del incremento cultural y educativo de la población que conduce a una igualación hacia arriba; no tiene en cuenta las altas tasas de movilidad social de las sociedades industriales; forma parte del pesimismo de los intelectuales elitistas por perder ese elitismo, ya no son los únicos que tienen "cultura"; la distinción entre élite y masa de la sociedad global, es demasiado burda como para tenerla en cuenta desde un punto de vista riguroso; por último, no se puede compaginar la idea de una ideología dominante (una sola ideología para toda la población) con la de conciencia de clase (cada clase social desarrolla su propia ideología). En resumen, difícilmente puede ser mantenida la tesis de la dominación al margen del enfoque del individualismo metodológico².

De cualquier forma, y con independencia del modelo explicativo utilizado, la explicación a la adscripción a valores no puede buscarse principalmente por el ámbito social del análisis. Son muchos los trabajos empíricos que, pese a haberlo intentado, no han ido muy lejos en esa relación causal ${ }^{3}$.

\footnotetext{
${ }^{2}$ Una fórmula intermedia entre la de dominación y la de la opción racional es la que proporciona Turner (1972). Como se recordará, este autor propone dos sistemas sociales diferenciados por dos modos de promoción: el de la movilidad de competencia (cuyo tipo ideal es EE.UU.), y el de la movilidad de promoción (cuyo tipo ideal fue, en su momento, Inglaterra). A su vez, en cada uno de esos sistemas sociales ideales se han desarrollado dos mecanismos de lealtad para con el sistema: el de la élite y el del resto de la población. El mecanismo de lealtad para la población desfavorecida en el sistema de competición radica en la propia ambición y creencia en que el juego competitivo pudiera proporcionarle un hueco en las posiciones favorecidas. Cuando el individuo toma conciencia de que no tiene acceso entre los favorecidos es ya demasiado tarde y él tiene demasiada edad como para enfrentarse al sistema. Por su parte la legitimación del sistema de promoción se consigue mediante una educación separada totalmente de la élite desde muy temprana edad, de forma que los individuos pertenecientes a las clases populares pueda percatarse claramente de las diferencias y méritos entre ellos y la élite. Así se justifica la posición dirigente de ésta élite.

${ }^{3}$ No obstante lo anterior, el desarrollo económico y la modernización (ámbito social) parecen proporcionar una explicación plausible a las diferencias de valores entre países (López-Casero y Waldmann, 1994; Alonso Zaldívar y Castells, 1992: 38-47; Bericat Alastuey, 1989). La distinción ya clásica entre materialismo y postmaterialismo (ámbito cultural) descansa en el diferente grado de desarrollo de la sociedad (Inglehart, 1991; Díez Nicolás, 1994). Asimismo, la diferenciación generacional también parece ser un elemento explicativo importante como mecanismo de cambio cultural (Montero y Torcal, 1994; López Pintor, 1994). El nivel educativo es también otra variable ligeramente relacionada con las respuestas a las preguntas sobre valores, pero poco más. Además,
} 


\section{RIS}

\section{El ámbito cultural}

La explicación, aquí y ahora, es independiente del ámbito social y del de la personalidad; tiene su propia dinámica. El ámbito cultural está formado por tres elementos: primero, el cognitivo; segundo, la cultura arbitraria, y tercero, la coherencia cultural. En otras palabras, el actor se ve presionado a actuar empujado por estos tres elementos del ámbito cultural, elementos que lo conforman y agotan básicamente. $\mathrm{Al}$ igual que antes, esta clasificación de elementos sigue siendo analítica. La realidad es un conglomerado difuso de todos ellos. Hay que tener en cuenta, además, que lo normal es un tránsito constante entre tales categorías; por ejemplo, el conocimiento científico puede llegar a constituirse como instrumento de distinción (cultura arbitraria), o la creencia (cultura arbitraria) puede llegar a transformarse en certeza y operar entonces como conocimiento a 1a hora de explicar el comportamiento humano. De cualquier forma, esa distinción sigue siendo útil.

\section{Conocimiento}

En primer lugar, en todo comportamiento existe una presión emanada del conocimiento real del entorno. Este elemento cultural se forma a partir del reflejo de la realidad. Denominamos conocimiento real a aquél que es revalidable mediante observación a través de los sentidos. De este conocimiento se puede afirmar que es verdadero o falso. La cantidad de conocimientos reales que tenga un individuo influirá por lo tanto en el comportamiento en cuestión. Así, el conocimiento sociológico sobre la sociedad influye en nuestra definición de la sociedad ideal (o en la falta de idealidad social) ${ }^{4}$.

\footnotetext{
el estudio de la adscripción a valores en función de la estructura social no ha dejado de tener su interés. Así, entre otros, hay que destacar el trabajo de Díez Nicolás (1992) en el que se explica la adscripción a valores postmaterialistas en función de la edad, la posición social según Galtung y la exposición a los medios de comunicación. El autor llega a explicar un 19 por ciento de la varianza. Otro ejemplo de explicación de adscripción a valores nacionalistas, en este caso, se encuentra en Herranz de Rafael (1996), que lo hace en función de la edad, la identificación ideológica, la educación, la práctica religiosa, el tipo de hábitat, los ingresos, la clase social subjetiva y el tipo de trabajo.

${ }^{4}$ Es un lugar común en la sociología actual suponer que la sociedad moderna se caracteriza por su reflexividad (Lamo de Espinosa, 1990), es decir que los conocimientos influyen más sobre el comportamiento en la sociedad moderna que en la tradicional. Posiblemente la influencia sea semejante, lo que varía es la cantidad y calidad de la información que se acumula en cada actor (véanse a título de ejemplo, Boltanski, 1974; Bott, 1990: 237-260). Esto puede llevar a su vez a una menor importancia de la información, dado su exceso, como guía de comportamiento.
} 
La opinión que se defiende aquí es que los conocimientos siempre han influido en la organización social y en la ideología adoptada sobre tal organización social. Lo que varía, tanto a lo largo del tiempo como a lo ancho de la población, es la cantidad y la calidad de los conocimientos. Y es ahí donde radica la complejidad del análisis de este elemento cultural, en la calidad de los conocimientos. Se pueden tomar como verdadero, real, es decir por conocimiento en sentido estricto, ideas que posteriormente pueden ser rechazadas como tales. Son muy abundantes las ideas que en su momento se consideraron conocimientos reales y que posteriormente se demostraron que eran radicalmente falsas. No por eso dejan de ser conocimientos en su momento de aceptación. Se comportan entonces esas ideas como auténticos conocimientos. Habría incluso que añadir en esta categoría las certezas adquiridas en el proceso de socialización primaria, tal y como las describen Berger y Luckmann (1986: 171).

La calidad del conocimiento tiene que ver con la calidad y velocidad de la difusión de los mismos. Y en este aspecto la escuela desempeña un papel fundamental. En la medida en que la escuela cumple la función de incrementar este tipo de conocimiento, el nivel educativo influirá sobre este aspecto cultural del comportamiento. Snyders (1978: 65) llamaba a este proceso escolar "formación para la verdad", que constituye una realidad pese a los negros augurios de Bourdieu y Passeron. Incluso, de acuerdo con Piaget (1972: 39-48), el desarrollo de la capacidad de abstracción en ciertos niveles depende del tiempo de escolarización. Los propios autores del estudio de valores de Andalucía (Pino y Bericat, 1998: 271) destacan la necesidad de un nivel educativo alto entre la población para participar activamente en política "por cuanto la política constituye una actividad sobre el sistema social general que requiere amplias dotes de capacitación cultural abstracta". Sin embargo, el nivel educativo (utilizado aquí como indicador del conocimiento) influye también poco en la adscripción a valores.

\section{Cultura arbitraria}

En segundo lugar, hay otro tipo de presión del ámbito cultural formado por aspectos de los que no se puede predicar si son verdaderos o falsos. Constituye lo que se ha dado en llamar la cultura arbitraria, es decir aquella cultura que no tiene que ver con la naturaleza de las cosas. Los aspectos culturales no instrumentales, integradores, no racionales, conforman la cultura arbitraria. Tradicionalmente los sociólogos han reducido la función de esta cultura arbitraria bien a la integración social (Durkheim, 1982; Alexander, ed. 1988), bien a la función de dominación (Bourdieu, 1988). Nuestro principal interés recae en la cultura arbitraria como factor explicativo. El próximo epígrafe estará dedicado a ella, por lo que ahora simplemente será mencionada.

Son muchos los autores que han distinguido entre esos dos conjuntos de elementos culturales, los cognitivos y los arbitrarios. Así, por ejemplo, Parsons (1976:18) 
RIS

REVISTA INTERNACIONAL DE SOCIOLOCIA

№ 33, Septiembre-Diciembre, 2002

RAFAEL GOBERNADO ARRIBAS

-orientación cognitiva y orientación catética o expresiva - o también Bernstein (1988) siguiendo de nuevo a Parsons - comportamiento instrumental y comportamiento expresivo- . Todos ellos tienen un común origen: Durkheim y su estudio sobre Las formas elementales de la vida religiosa. La influencia de la clasificación de Durkheim ha ido mucho más allá de lo reconocido. Alexander (1990) constata tal influencia en autores que incluso no lo han declarado, desde los franceses Saussure y Levi-Strauss hasta los norteamericanos y discípulos de Parsons, Shils y Geertz.

\section{Coherencia cultural}

Hay un tercer tipo de influencia cultural en el comportamiento estudiado. Se trata de la interacción entre los elementos instrumentales y los elementos expresivos. Es por lo tanto un tipo mixto, más que un tipo puro. Parsons (1976: 19) hablaba entonces de orientación evaluativa. En realidad se trata de la presión que sufre el actor para actuar de forma medianamente coherente, de acuerdo tanto con los dictados cognitivos como con los expresivos. Hay un cierto orden, jerarquía o sistema de importancias que empuja en una u otra dirección. La idea de coherencia cultural ha sido abundantemente debatida, aunque no tanto su existencia real como el origen de la percepción de tal coherencia (Smelser, 1992). Así, unos han entendido que es el resultado de procesos psicológicos que influyen en la organización cultural (Malinowski, 1974); para otros, es resultado también de procesos psicológicos, pero cuya razón de ser se encuentra en la necesidad de dar sentido a la vida (Geertz, 1973); otros han dirigido la atención a la presión que ejerce la estructura social sobre la cultura, que obliga a ésta a esa coherencia (Parsons, 1976 y su noción de ideología); otros la ven como consecuencia del desarrollo lógico de una serie de premisas culturales importantes, de las que se deducen sistemáticamente el resto de elementos culturales (Sorokin, 1962); los hay que piensan que es la dominación de unos sobre otros lo que obliga a tal sistematización (así, los autores que se basan en el planteamiento de la Ideología alemana de Marx); por último están los que piensan que la coherencia cultural sólo se encuentra en la cabeza del investigador (el propio Smelser, 1992).

De cualquier forma, sí parece haber una presión hacia la coherencia en el comportamiento humano, con independencia del origen de tal presión. Damos por supuesto que la presión hacia la coherencia proviene tanto de los conocimientos reales sobre el entorno y de la capacidad de abstracción, como de la cultura arbitraria que incorporan. La presión en este caso será mayor cuanto más alto sea el nivel educativo y más aceptados estén los valores en la población correspondiente. No obstante, parece difícil que la coherencia cultural tenga más importancia explicativa que las otras dos fuentes de adscripción a valores de donde procede. 


\section{El ámbito de la personalidad}

El ámbito de la personaldad cae fuera de nuestros intereses. Es obvio que la personalidad tiene que explicar en una alta proporción la elección de una respuesta $\mathrm{u}$ otra a las preguntas sobre valores. Pero en lo que concierne a este trabajo, se trata de una categoría residual. El resto, lo no explicable según nuestros criterios, debe ser achacado a la personalidad del actor.

En el ámbito de la personalidad se encuentran dos niveles unidos: la presión del entorno y la carga genética. Son muchos los autores que encuentran lazos de unión entre el elemento biológico de la personalidad y el ámbito cultural. Existe una polémica que viene de antiguo, por lo menos desde Platón, sobre la relación entre inteligencia y herencia genética. Aunque el concepto de inteligencia sea difícil de definir, parece claro que la herencia biológica tiene algo que ver con la inteligencia y con la capacidad de aprender conocimientos (Eysenck, 1987). También de antiguo viene la idea de que la cultura arbitraria, en particular los mitos, ritos y ceremonias, está muy ligada a la biología humana (Halton, 1992). No es este el momento para dedicar atención a tan sugestivo tema.

\section{LA CULTURA ARBITRARIA}

La cultura arbitraria, como se apuntó arriba, constituye la principal explicación de la adscripción a valores, según nuestro criterio. Son los franceses Bourdieu y Passeron (1981: 48) los que han definido de manera más contundente el concepto en cuestión. Dicen estos autores en su conocido libro La reproducción (cuya primera edición es de 1970) que la cultura "[...] es arbitraria en tanto que la estructura y las funciones de esta cultura no pueden deducirse de ningún principio universal, físico, biológico o espiritual, puesto que no están unidas por ningún tipo de relación interna a la naturaleza de las cosas o a una naturaleza humana".

La idea de que muchos elementos culturales son arbitrarios ha sido compartida en general por todo el estructuralismo cultural, así como por los análisis semiológicos del lenguaje. Precisamente Giddens (1990: 74), feroz crítico del estructuralismo francés, destaca dos rasgos característicos de esta escuela teórica que vienen al hilo de la cuestión: el análisis propio del estructuralismo se basa en el carácter arbitrario del signo y en la primacía del significante sobre el significado. Pero no sólo ha sido compartida la idea de la arbitrariedad cultural por los estructuralistas franceses, sino también por otros muchos autores ajenos a tal tipo de planteamiento teórico. La arbitrariedad en la cultura ha de implicar por lo menos un cierto caos cultural. Y precisamente en ese caos hace hincapié Schmid (1992), colaborador en la recopilación de lecturas de Smelser y Münch (1992) sobre teoría de la cultura. Ese autor propone tres presupuestos teóricos de todo análisis cultural. a) La cultura está formada por una gran variedad y complejidad 


\section{RIS}

de elementos; lo normal es el desajuste, la incongruencia y la inconsistencia entre los mismos. b) Se debe mantener una estricta separación entre el sistema social y el cultural; el sistema social puede estar más o menos integrado con independencia de que el sistema cultural sea más o menos internamente congruente. c) La dinámica cultural es un proceso constante recursivo de desequilibrio; en este proceso no sólo hay acumulación e integración, sino también "revoluciones culturales", pérdidas abruptas de tradiciones, rupturas de estructuras y muchas otras formas de transformaciones discontinuas.

Verdaderamente, lo que ha hecho este autor ha sido proporcionar más claves para la comprensión de la cultura arbitraria. Y algo parecido ocurre con la noción de cultura de otro conocido sociólogo, colaborador en la recopilación citada, Eisenstadt (1992: 68). Afirma este autor que la cultura, en gran medida, es una construcción artificial encaminada a evitar la incertidumbre, desazón y angustia que el simple hecho de vivir provoca en los humanos. Sin embargo, añade, es muy difícil mantener esa artificialidad sin que los humanos tomen conciencia de la misma, sin que descubran el engaño. Por ello, continuamente están surgiendo intentos de afianzamiento de tal cultura o, en su caso, de sustitución de la misma. Llega a afirmar Eisenstad que transformación y mantenimiento del orden cultural son cara y cruz de una misma moneda (1992-73). En otras palabras, la propia cultura genera a la vez la integración y la protesta, protesta que puede llegar incluso al cambio y la revolución. La idea básica de nuestro trabajo va más allá de estos autores: la diversidad cultural, integración y protesta, en una población determinada no sólo es inevitable, sino también deseable.

El mecanismo de diversificación cultural que aquí se propone está formada por el proceso constante y contradictorio de distinción e identificación $n^{5}$. En la medida en que el actor se mueve a través de la cultura arbitraria, pretende mediante su comportamiento un doble objetivo: identificarse con otros iguales $\mathrm{y}$, al mismo tiempo, distinguirse de los demás. El proceso se produce tanto entre individuos como entre colectivos; tanto en el nivel microsocial como en el macrosocial. Se produce y reproduce constantemente. La distinción y la identificación sólo se

\footnotetext{
${ }^{5}$ Los conceptos de distinción e identificación han sido estudiados abundantemente en la bibliografía sociológica. En general han sido tratados por separado: la distinción (Bourdieu, 1988; Boudon, 1981: 173-180; Veblen, 1974) como rasgo característico de la élite se ha contrapuesto generalmente a la idea de 'masa'. Por su parte, la identificación (Alexander, 1988; Valcárcel, 1995) se contrapone habitualmente al individualismo o a la alienación.

También han sido tratados conjuntamente, especialmente en áreas próximas a la psicología social. Un resumen de las teorías sobre identidad colectiva y la distinción frente a los otros se encuentra en Javaloy, Rodríguez y Espelt (2001:291-344). En el área estrictamente sociológica seguramente debemos a Simmel el primer tratamiento conjunto del tema en su teoría de la moda. El francés Tarde expuso ideas parecidas a las de Simmel. Boudon se encargó de formalizar ambas (1981: 176-178).
} 
pueden producir en el nivel cultural, ya que son conceptos propios de la ideacionalidad. De acuerdo con esa dinámica, no puede haber un acuerdo muy amplio dentro de cualquier sociedad, grupo o categoría social, sobre aquellos elementos de la cultura que hemos definido como arbitrarios. El desacuerdo se manifiesta como un instrumento eficaz de distinción 6 .

Esta dinámica constante de unión y desunión da lugar a una ruptura constante entre individuos y grupos. Da lugar a una diversidad cultural provocada. Los procesos de identificación y de distinción son mecanismos específicamente desarrollados para crear diversidad cultural. La diversidad cultural ha de entenderse como una estrategia adaptativa que ha demostrado su eficacia. Posiblemente han sobrevivido mejor los grupos con culturas internamente diversificadas, que los grupos con culturas internamente homogéneas (en el caso de que estos hayan existido alguna vez). Es útil que en todo grupo, categoría social o cualquiera qưe sea la unidad social, haya alternativas culturales a la cultura generalmente aceptada. De esa manera siempre habrá posibles sustitutos en caso de cambio drástico de ambiente. Esto da lugar a la constante protesta de la que hablaba Eisenstadt, pero sin necesidad de justificarla en ansiedades, incertidumbres y trascendencias humanas como hace ese autor (1992: 67): la propia dinámica cultural da lugar a tal diversidad?.

${ }^{6}$ La teoría general de sistemas parece describir mejor la relación entre identificación y distinción. Así ocurre con las nociones de identidad y diferencia, en particular con la idea que de ellas da Luhmann (1998a:31-57; 1998b:71-98). Ese constante proceso de identificación y diferenciación lo consiguen los sistemas autorreferenciales mediante la delimitación constante del sistema y su entorno. Pese a que los planteamientos de $\mathrm{N}$. Luhmann son muy sugerentes y están muy relacionados con la hipótesis central de nuestro trabajo, sin embargo la noción de sistema social de Luhmann, ajena en gran medida a la de sistema psiquico, hace que no podamos recurrir a su obra como apoyo teórico. Para una crítica de ese aspecto de la obra de Luhman véase Halton (1992).

${ }^{7}$ Existe una fórmula (Cohen, 1985: 12-20) para unificar sentimientos y afectividades alrededor de los símbolos comunales (otra arbitrariedad cultural). Como se sabe, el mantenimiento de la comunidad se basa en la semenjanza interna (idenficación) y la diferenciación externa (distinción). En verdad, los individuos de cualquier comunidad se diferencian entre sí tanto como con los de fuera. Para evitar el rompimiento de ese sentimiento de semejanza interna los miembros marcan los límites de la comunidad mediante símbolos que les identifican. La particularidad de los símbolos es que se forman a partir de dos elementos: uno es el significante, perceptible mediante los sentidos, material; otro invisible que es el significado adscrito al elemento material anterior. El significado lo lleva cada cual en su interior, y seguramente difiere de una mente a otra. Lo único que se ve es lo que todos aprecian en común, lo externo, lo material y en lo que todos están de acuerdo, es decir el significante. De esta manera, las ideas individuales y diferentes (el significado) pueden convivir con lo colectivo (el significante). El problema surge cuando las personas toman conciencia de esa arbitrariedad, y el artificio deja de surtir efecto. Es entonces cuando la cultura arbitraria da lugar a conflictos y protestas (Eisenstadt, 1992). 
RIS

REVISTA INTERNACIONAL DE SOCIOLOCIA

№ 33, Septiembre-Diciembre, 2002

RAFAEL GOBERNADO ARRIBAS

Se aprecia, de acuerdo con lo anterior, un proceso de rompimiento, de división cultural. Esta división se efectúa según una tendencia hacia la polarización, entendiendo por tal el proceso de ubicarse en situaciones opuestas. Y es aquí donde cobran importancia los valores. Los valores son principalmente criterios de preferibilidad (Williams, 1979: 16; Pino y Bericat, 1998: 2). Los actores prefieren unas cosas a otras, unas ideas a otras, unos ideales a otros. Precisamente, lo que les da una singular importancia en el campo de la cultura arbitraria es la polaridad que incluyen. Todos los teóricos de los valores hacen hincapié en ese rasgo característico suyo: un valor sólo existe en la medida en que existe su contrario. La belleza junto a la fealdad; la bondad junto a la maldad, etc. (Ferrater Mora, 1979: 3.376; Marías, 1980: 408; Frondizi, 1972: 19; William, 1977). Incluso la polarización va más allá: se produce también entre posturas radicales y posturas moderadas frente a un mismo valor. Es decir, no sólo se escoge en uno u otro sentido del valor cuestionado, sino que se escoge además entre una actitud extremista y otra indiferente.

Se trata de un campo espléndido para evidenciar la elección en función de la identificación y de la distinción. Además, de los valores, en la medida en que forman parte de la cultura arbitraria, no se puede decir que sean verdaderos o falsos, sino si son estimados o no por los actores. No existe un referente objetivo con el cual comparar. Constituyen, así pues, el ideal de la cultura arbitraria. Se puede afirmar, por lo tanto que su principal función en el ámbito de la cultura arbitraria es el de la identificación y el de la distinción.

De acuerdo con lo anterior, el concepto de polarización se convierte en fundamental. Se entiende por polarización la tendencia a ubicarse en los extremos de la distribución ${ }^{8}$. En general, en los estudios sobre valores a lo más que se llega es a describir la distribución de preferencias entre la población, distribución que a menudo se observa polarizada. Sin embargo tal polarización no ha sido objeto directo de análisis. Incluso cuando se establecen relaciones entre variables, se parte de la base de una relación, bien lineal o bien nominal, entre la variable independiente y la respuesta pertinente a la pregunta sobre valores (a título de muestra véase la mayor parte de los trabajos publicados en Díez Nicolás y Inglehart, 1994; y en Kaiero Uría, 1994; también, Andrés Orizo, 1996). No se ha tenido necesidad de observar el proceso de polarización. A lo más que se ha llegado es a utilizar los valores extremos de la variable dependiente como indicador de carga emocional (Pino Artacho y Bericat, 1998: 33).

\footnotetext{
${ }^{8}$ Escobar (1998:10) llama la atención sobre tres dimensiones de la diversidad que pueden llegar a confundirse: La desviación o distancia con respecto a un punto de referencia (en general la media aritmética); la desigualdad o distancia recíproca entre todos los sujetos de la población; y la polarización o tendencia a ubicarse en los extremos de la distribución.
} 
Por el contrario, en los análisis de ciencia política y, en particular, en los estudios sobre opinión pública, se dedica mucha atención a procesos como los de polarización, fragmentación y división ${ }^{9}$. La idea de ruptura, o línea de separación entre dos extremos o polos, es habitual en este tipo de análisis (véase, por ejemplo, Torcal y Chhibber, 1995 y DiMaggio, Evans y Bryson, 1996). La opinión pública presenta habitualmente una distribución en forma de campana invertida o una rama de ésta (Sierra Bravo, 1998: 388). De acuerdo con esto, las respuestas sobre valores difieren claramente de las respuestas sobre opinión pública: la opinión pública no siempre implica enfrentamiento de opiniones sobre un asunto (distribución en forma de ' $U$ '), sino también consenso sobre el tema (distribución en forma de ' $J$ ' o ' $L$ '), mientras que las respuestas sobre valores están mayoritariamente polarizadas.

\section{MODERNIZACIÓN Y CULTURA ARBITRARIA}

Hasta aquí se ha considerado la existencia de la cultura arbitraria de forma totalmente independiente del sistema social. Obviamente esto no es del todo cierto. La relación entre los dos ámbitos, el social y el cultural, va a permitirnos introducir un elemento dinámico en nuestro análisis de la cultura arbitraria: el cambio de la misma a medida que tiene lugar el desarrollo de la modernización. La modernización, en lo que concierne a este trabajo, se aprecia fundamentalmente en dos procesos paralelos e interrelacionados: a) el aumento de la complejidad del ámbito social; y b) la creciente independencia del ámbito cultural respecto del social.

La complejidad del ámbito social (véase, entre otros, Durkheim, 1973; Eisenstadt, 1992; Smelser, 1971; Treiman, 1970) se aprecia, a su vez, en otros tres: a) la multiplicación del número de posiciones sociales que lo definen; $b$ ) el aumento de posiciones a las que pertenece un mismo individuo, y c) el incremento de movilidad entre posiciones. La complejidad social da lugar a la individuación, proceso propio del ámbito social que indica el hecho de que cada vez sea más difícil predecir el comportamiento de una persona a partir de las posiciones sociales que ocupa debido, precisamente, a los cambios del nivel social apuntados arriba. Así, por ejemplo, la práctica religiosa, la dirección de voto, el estilo de vida, cada vez se explican menos a partir de la clase ocupacional, del nivel educativo, del nivel de renta, etc.

\footnotetext{
${ }^{9}$ A medio camino entre los análisis de ciencia política y los de cultura merece citarse el libro editado por Berger (1999) formado por diversos informes para el Club de Roma en los que la idea central es la de polarización y conflicto cultural en el Estado.
} 
RIS

REVISTA INTERNACIONAL DE SOCIOLOGIA

№ 33, Septiembre-Diciembre, 2002

RAFAEL GOBERNADO ARRIBAS

Por su parte, la modernización influye en el ámbito cultural (véase, entre otros, Solé, 1976; Sebreli, 1992; Germani, 1991; Halman y Moor, 1994) de cuatro formas básicas: a) aumentando la cantidad de conocimientos reales o verificables; b) aumentando la velocidad de transmisión de los elementos culturales; c) desacralizando los elementos culturales propios de la integración, y d) desarrollando el sentimiento individualista.

La modernización influye de dos maneras decisivas en la formación de la cultura arbitraria. En primer lugar, el proceso de individuación citado arriba justifica que el nivel cultural se independice del social. Se supone que en una sociedad tradicional, con una división del trabajo poco compleja, la posición social condiciona el nivel cultural. Incluso que la práctica de la distinción y de la identificación se obtiene a partir de la pertenencia a posiciones sociales. En la medida en que aumenta la complejidad y da lugar a la individuación, la identificación y la distinción se consiguen en mayor proporción al margen de la estructura de posiciones sociales. Esto no significa que aumente la proporción de cultura denominada arbitraria en las sociedades complejas, sino que tal cultura arbitraria se vuelve más independiente y flexible. A ello ayuda además la desacralización de los elementos arbitrarios de la cultura. Al mismo tiempo, el sentimiento individualista facilita, e incluso fomenta, el interés por la distinción.

En segundo lugar, en las sociedades modernas, a falta del apoyo en la estructura social, esa presión hacia la polaridad cultural proviene sobre todo del proceso de interacción cotidiana (en donde ha de incluirse, además, la influencia de los medios de comunicación social). Es decir, la polarización se apoya cada vez más en la interacción cotidiana. Hay que buscar cada vez más su explicación en el nivel microsocial de análisis, e incluso se vuelve más individual que colectiva a medida que se produce la modernización. Así, por ejemplo, cualquier conversación entre amigos sobre las ventajas y desventajas del libre mercado se polariza rápidamente con argumentos contradictorios debido más a la dinámica de la tertulia que a las ventajas o desventajas reales del libre mercado.

La polarización valorativa, como ya se comentó, se produce y reproduce en múltiples niveles: entre los extremos del sentido valorativo, en el nivel microsocial y en el macro, y entre la moderación y la radicalidad. Por ello, la polarización valorativa de una comunidad moderna, de acuerdo con la definición de ésta dada arriba, no puede ser demasiado acusada, a diferencia de la opinión pública. En la opinión pública moderna, por el contrario, se admiten todas las posibilidades: desde el acuerdo mayoritario sobre un tema, al desacuerdo y enfrentamiento acusado sobre el mismo. La propia lógica de la polarización múltiple (identificación y distinción) impide la existencia de claras divisiones entre la población por culpa de los valores. 


\section{CONCLUSIONES}

El presente trabajo se mueve en el ámbito de lo teórico. Ofrece un modelo explicativo de la adscripción a valores que es generalizable a los demás componentes de la cultura. Tradicionalmente se ha querido explicar la adscripción a valores (nivel de análisis cultural) según las categorías sociales de pertenencia de los individuos (nivel social de análisis). Los resultados han sido en todos los casos más bien pobres. Esto es debido a que el nivel cultural es relativamente independiente del nivel social. Se guía por su propia lógica. Este trabajo está dedicado a descubrir esa lógica interna de funcionamiento de la cultura, sin olvidar que algo tiene que ver con los demás subsistemas que explican la acción social: la biología, la personalidad y la sociedad.

En primer lugar, se han precisado los elementos abstractos que integran la cultura: "los conocimientos", "la cultura arbitraria" y "la coherencia cultural". Se entiende por conocimiento aquel que es revalidable mediante observación a través de los sentidos. De este elemento se puede afirmar que es verdadero o falso. Por el contrario, la cultura arbitraria es aquella que no tiene que ver con la naturaleza de las cosas. De ella no se puede predicar que sea verdadera o falsa, sino si está aceptada por la población o no. Por su parte, la coherencia cultural es la presión que sufre el actor para conjugar internamente los elementos cognitivos y los arbitrarios. Se trata de abstracciones. En cualquier manifestación ideacional se puede apreciar conjuntamente el aspecto cognitivo, el arbitrario y la coherencia interna. Son, además, categorías muy dinámicas: se produce una constante transformación de tales elementos; así, por ejemplo, los conocimientos científicos pueden terminar por ser fuente de distinción e identificación, al igual que la coherencia cultural; por su parte, la cultura arbitraria puede transformarse en creencia, léase certeza indiscutible, y comienza a funcionar como si fuera conocimiento, etc.

De todos los elementos repasados, la cultura arbitraria es el que más ha atraído nuestra atención. La cultura arbitraria está formada por aquellos contenidos culturales que son independientes de la naturaleza de las cosas. El mecanismo de cristalización de ese elemento cultural se encuentra en los procesos de distinción e identificación que tienen lugar tanto en un nivel individual como colectivo, microsocial como macrosocial. Mediante la cultura arbitraria el individuo pretende identificarse con sus iguales, al mismo tiempo que trata de distinguirse de ellos. La consecuencia inmediata de tal mecanismo es la aparición constante de polarización cultural, si bien atenuada por la complejidad de sus fuentes.

$\mathrm{El}$ análisis de la adscripción a valores desarrollado en estas páginas permite apreciar la influencia de cada uno de los componentes culturales así como de los demás subsistemas con los que se relaciona (el social, el de la personalidad y el biológico) en la construcción y deconstrucción de los valores. En la adscripción a valores se entrecruzan el interés, el afán de dominación, los conocimientos, la polarización y la coherencia cultural. Seguramente, los estudios empíricos de 
la adscripción a valores evidenciarán la importancia del elemento arbitrario en la cultura. En la medida en que los valores participan de esa arbitrariedad cultural, la aceptación de los mismos por parte de la población implica una cierta cantidad de polarización. Ahora bien, esa polarización no puede ser extrema ya que se produce en múltiples dimensiones (individual o colectiva; microsocial o macrosocial; actitudes extremas o moderadas), por lo que se compensan los resultados globales. Precisamente este comportamiento es el que distingue las respuestas sobre valores de las respuestas sobre opinión pública. La distribución de la opinión pública puede estar o no polarizada, ya que en muchas oportunidades existe un consenso mayoritario sobre el asunto objeto de opinión, mientras que, las respuestas a valores siempre presentan polarización.

\section{BIBLIOGRAFÍA}

ADORNO, T.W. y M. HORKHEIMER (1971), Dialéctica del iluminismo, Buenos Aires, Sur (1 ${ }^{\mathrm{a}}$ edición en 1944).

ALEXANDER, J.C. (ed.) (1988), Durkheimian Sociology: Cultural Studies, Cambridge, Cambridge University Press.

ALEXANDER, J.C. (1988) "Introduction: Durkheimian Sociology and Cultural Studies Today", en J.C. Alexander (ed.), Durkheimian Sociology: Cultural Studies, Cambridge, Cambridge University Press, pp. 1-22.

ALONSO ZALDIVAR, C. y M. CASTELLS (1992), España fin de siglo, Madrid, Alianza.

ANDRÉS ORIZO, F. (1994), "Los valores de los españoles", en A. Kaireo Uría (ed.), Valores y estilos de vida de nuestra sociedad en transformación, Bilbao, Universidad de Deusto, pp. 57-85.

ANDRÉS ORIZO, F. (1996), Sistema de valores en la España de los 90, Madrid, C.I.S.

BAUDRILLARD, J. (1974), La sociedad de consumo, Barcelona, Plaza y Janés, (1ª, 1944).

BERGER, P.L. (ed.) (1999), Los límites de la cohesión social. Conflictos y mediación en las sociedades pluralistas, Barcelona, Círculo de Lectores.

BERGER, P.L. y Th. LUCKMANN (1986), La construcción social de la realidad, Madrid, Amorrortu.

BERICAT ALASTUEY, E. (1989), "Cultura productiva y desarrollo endógeno. El caso andaluz", Revista de Estudios Regionales, n²4, pp. 15-43.

BERSTEIN, B. (1988), Clases, códigos y control. II. Hacia una teoria de las transmisiones educativas, Madrid, Akal.

BOLTANSKI, L. (1974), Puericultura y moral de clase, Barcelona, Laia (1 $1^{\text {a }}$ edición de 1969). 
BOTT, E. (1990), Familia y red social, Madrid, Taurus, (1ª edición de 1971).

BOUDON, R. (1979), Effets pervers et ordre social, París, P.U.F.

(1981), La lógica de lo social, Madrid, Rialp.

BOURDIEU, P. (1988), La distinción, Madrid, Taurus (1ª edición en 1979).

BOURDIEU, P. y J.C. PASSERON (1981), La reproducción, Barcelona, Laia (1 $1^{\text {a }}$ edición en 1970).

DEL PINO ARTACHO, J. y E. BERICAT ALASTUEY (1998), Valores sociales en la cultura andaluza. Encuesta Mundial de Valores. Andalucía 1996, Madrid, C.I.S.

DÍEZ NICOLÁS, J. (1992), "Posición social, información y postmaterialismo”, Revista Española de Investigaciones Sociológicas, $\mathrm{n}^{\circ}$ 57, pp. 21-35.

(1994), "Post-materialismo y desarrollo económico en España”, en Díez Nicolás, J. y R. Inglehart (ed.), Tendencias mundiales de cambio en los valores sociales y politicos, Madrid, Fundesco, pp. 125-156.

DÍEZ NICOLÁS, J. y R. INGLEHART (ed.) (1994), Tendencias mundiales de cambio en los valores sociales y politicos, Madrid, Fundesco.

DIMAGGIO, P., J. EVANS y B. BRYSON (1996), “Have Americans' Social Attitudes Become More Polarized?", American Journal of Sociology, n 3, pp. 690-755.

DURKHEIM, E. (1982), Las formas elementales de la vida religiosa, Madrid, Akal ( $1^{\text {a }}$ edición en 1912).

EISENSTADT, S.N. (1992a), "Estudios de modernización y teoría sociológica", en T. Carnero Arbat (ed.), Modernización, desarrollo político y cambio social, Madrid, Alianza, pp. 71-100.

(1992b), "The Order-maintaining and Order-transforming Dimensions o Culture", en R. Münch y N. J. Smelser (eds.), Theory of Culture, Berkeley, University of California Press, pp. 64-87.

ESCOBAR, M. (1998), "Desviación, desigualdad, polarización: medidas de la diversidad social”, Revista Española de Investigaciones Sociológicas, $\mathrm{n}^{\circ}$ 82, pp. 9-36.

EYSENCK, H.J. (1987), La desigualdad del hombre, Madrid, Alianza (1 $1^{\text {a }}$ edición en 1973).

FEATHERSTONE, M. (1992), "Cultural Production, Consumption, and the Development of the Cultural Sphere", en R. Münch y N.J. Smelser (eds.), Theory of Culture, Berkeley, University of California Press, pp. 265- 289.

FERRATER MORA, J. (1979), Diccionario de filosofia, T. 4, Madrid, Alianza.

FRONDIZI, R. (1972), ¿Qué son los valores?, Méjico, F.C.E. (1ª edición en 1958). 
GEERTZ, Cl. (1973), The Interpretation of Cultures: Selected Essays, Nueva York, Basic Books.

GIDDENS, A (1990), Social Theory and Modern Sociology, Cambridge, Polity Press.

HALMAN, L. y R. MOOR, (1994), "Individualización y cambio de valores en Europa y Norteamérica", en J. Díez Nicolás y R. Inglehart (eds.), Tendencias mundiales de cambio en los valores sociales y politicos, Madrid, Fundesco, pp. 29-62.

HALTON, E. (1992), “The Cultic Roots of Culture”, en R. Münch y N.J. Smelser (eds.), Theory of Culture, Berkeley, University of California Press, pp. 29-63.

HERRANZ DE RAFAEL, G. (1996), "Estructura social e identificación nacionalista en la España de los noventa”, Revista Española de Investigaciones Sociológicas, $\mathrm{n}^{\circ}$ 76, pp. 9-35.

INGLEHART, R. (1991), El cambio cultural en las sociedades occidentales avanzadas, Madrid, C.I.S.

(1994), "Modernización y post-modernización: la cambiante relación entre el desarrollo económico, cambio cultural y político", en J. Díez Nicolás, J. y R. Inglehart (eds.), Tendencias mundiales de cambio en los valores sociales y políticos, Madrid, Fundesco, pp. 63-108.

JAVALOY, F., A. RODRÍGUEZ y E. ESPELT (2001), Comportamiento colectivo y movimientos sociales, Madrid, Prentice Hall.

KAIERO URÍA, A. (ed.) (1994), Valores y estilos de vida de nuestra sociedad en transformación, Bilbao, Universidad de Deusto.

KERHOFS, J. (1994), "Evolución de los valores en Europa entre 1980 y 1990" en A. Kaiero Uría (ed.), Valores y estilos de vida de nuestra sociedad en transformación, Bilbao, Universidad de Deusto, pp. 453-456.

LAMO DE ESPINOSA, E. (1990), La sociedad reflexiva, Madrid, C.I.S.

LÓPEZ PINTOR, R. (1994), “Continuidades y discontinuidades en las actitudes de los españoles”, en F. López-Casero, W.L. Bernecker y P. Waldmann (comps.), El precio de la modernización. Formas y retos del cambio de valores en la España de hoy, Madrid, Iberoamericana, pp. 41-79.

LÓPEZ-CASERO, F. y P. WALDMANN (1994), "Introducción: reflexiones comparativas sobre el proceso de modernización en España”, en F. López-Casero, W.L. Bernecker y P. Waldmann, (comps.), El precio de la modernización. Formas y retos del cambio de valores en la España de hoy, Madrid, Iberoamericana, pp. 13-40.

LUHMANN, N. (1998a), Sistemas sociales. Lineamientos para una teoria general. Barcelona, Anthropos, Universidad Iberoamericana y Centro Editorial Javerino ( $1^{a}$ edición en 1984).

LUHMANN, N. (1998b), Complejidad y modernidad, Madrid, Trotta.

MALINOWSKI, B. (1974), Magia, ciencia, religión, Barcelona, Ariel (1ª edición en 1948).

MARCUSE, H. (1969), El hombre unidimensional, Barcelona, Seix Barral ( $1^{\mathrm{a}}$ edición en 1954).

64 
MARIAS, J. (1980), Historia de la filosofia, Madrid, Revista de Occidente.

MONTERO, J.R. y M. TORCAL (1994), "Cambio cultural, reemplazo generacional y política en España”, en J. Díez Nicolás y R. Inglehart (eds.), Tendencias mundiales de cambio en los valores sociales y politicos, Madrid, Fundesco, pp. 177-225.

MÜNCH, R. y S.J. SMELSER (1992), Theory of Culture, Berkeley, University of California Press.

PARSONS, T. (1976), "El sistema social”, Revista de Occidente (1 $1^{\text {a }}$ edición en 1951), Madrid.

PERRY, R.B. (1954), Realms of Value. A critique of Human Civilization, Cambridge, Mass., Harvard University Press.

PIAGET, J. (1972), Psicología y pedagogía, Barcelona, Ariel.

ROKEACH, M. (1979), Understanding Human Values. Individual and Societal, Nueva York, The Free Press.

ROS, M. y Sh. H. SCHWARTZ (1995), "Jerarquía de valores en Países de la Europa occidental: una comparación transcultural”, Revista Española de Investigaciones Sociológicas, $\mathrm{n}^{\circ} 69$, pp. 69-88.

SCHMID, M. (1992), "The Concept of Culture and its Place within a Theory of Social Action. A Critique of T. Parsons' Theory of Culture", en R. Münch y N.J. Smelser, Theory of Culture, Berkeley, University of California Press, pp. 88-120.

SEBRELI, J.J. (1992), El asedio a la modernidad. Critica del relativismo cultural, Barcelona, Ariel.

SIERRA BRAVO, R. (1998), Técnicas de investigación social. Teoría y ejercicios, Madrid, Paraninfo.

SMELSER, N.J. (1971), “Mecanismos de cambio y ajuste al cambio”, en B.F. Hoselitz y W.E. Moore (eds.), Industrialización y sociedad, Madrid, Euramérica, pp. 45-75.

(1992), “Culture: Coherent or Incoherent”, en R. Munch y N.J. Smelser (eds.), Theory of Culture, Berkeley, University of California Press, pp. 3-28.

SMITH, C.L. (1991), "Measures and Meaning in Comparisons of Wealth Equality", Social Indicators Research, $\mathrm{n}^{\circ} 24$, pp. 367-392.

SOLÉ, C. (1976), Modernización: un análisis sociológico, Barcelona, Península.

SOROKIN, P.A. (1962), Dinámica social y cultural, Madrid, Instituto de Estudios Políticos, vol. 2.

TORCAL LORIENTE, M. (1992), “Análisis dimensional y estudio de valores: El cambio cultural en España”, Revista Española de Investigaciones Sociológicas, $\mathrm{n}^{\circ}$ 58, pp. 97-122.

TORCAL LORIENTE, M. y P. CHHIBBER (1995), “Elites, cleavages y sistema de partidos en una 
RIS

democracia consolidada: España (1986-1992)", Revista Española de Investigaciones Sociológicas, $\mathrm{n}^{\circ} 69$, pp. $7-38$.

TREIMAN, D.J. (1970), "Industrialization and Social Stratification", en E.O. Laumann (ed.), Social Stratification: Research and Theory for the 1970s, Nueva York, The Bobbs-Merril Company, pp. 207-234.

VALCÁRCEL, A. (1995), "Las raices del principio igualdad" en R.M. Mate (coord.), Pensar la igualdad y la diferencia. Una reflexión filosófica, Madrid, Visor y Argentaria, pp. 65-76.

VEBLEN, Th. (1974), Teoria de la clase ociosa, Méjico, F.C.E. (1 $1^{a}$ edición en 1899).

WILLIAMS, R.M. (1977), “Valores”, en D.L. Sills (dir.), Enciclopedia Internacional de las Ciencias Sociales, vol. 10, pp 607-610, (1"a 1968).

(1979), "Change and Stability in Values and Value Systems: a Sociological Perspective", en M. Rokeacg (ed.), Understanding Human Values. Individual and Societal, Nueva York, The Free Press, pp. 15-46. 